\title{
Impact and cost of a 2-week community-based screening and awareness program for diabetes and cardiovascular risk factors in a Swiss canton
}

This article was published in the following Dove Press journal:

Diabetes, Metabolic Syndrome and Obesity:Targets and Therapy

15 June 2011

Number of times this article has been viewed

\author{
Pascal Bovet ${ }^{1}$ \\ Philippe Hirsiger ${ }^{2}$ \\ Frédéric Emery ${ }^{3}$ \\ Jessica De Bernardini² \\ Christophe Rossier ${ }^{3}$ \\ Josefine Trebeljahr ${ }^{2}$ \\ Isabelle Hagon-Traub ${ }^{2}$ \\ 'Institute of Social and Preventive \\ Medicine (IUMSP), University of \\ Lausanne and Centre Universitaire \\ Hospitalier Vaudois (CHUV), \\ Lausanne, Switzerland; ${ }^{2}$ Public Health \\ Service, Department of Health \\ and Social Action, Canton of Vaud, \\ Lausanne, Switzerland; ${ }^{3}$ Association \\ of Pharmacists, Canton of Vaud, \\ Lausanne, Switzerland
}

Background: Community-based diabetes screening programs can help sensitize the population and identify new cases. However, the impact of such programs is rarely assessed in high-income countries, where concurrent health information and screening opportunities are common place.

Intervention and methods: A 2-week screening and awareness campaign was organized as part of a new diabetes program in the canton of Vaud (population of 697,000) in Switzerland. Screening was performed without appointment in 190 out of 244 pharmacies in the canton at the subsidized cost of 10 Swiss Francs per participant. Screening included questions on risk behaviors, measurement of body mass index, blood pressure, blood cholesterol, random blood glucose (RBG), and A1c if RBG was $\geq 7.0 \mathrm{mmol} / \mathrm{L}$. A mass media campaign promoting physical activity and a healthy diet was channeled through several media, eg, 165 spots on radio, billboards in 250 public places, flyers in 360 public transport vehicles, and a dozen articles in several newspapers. A telephone survey in a representative sample of the population of the canton was performed after the campaign to evaluate the program.

Results: A total of 4222 participants $(0.76 \%$ of all persons aged $\geq 18$ years) underwent the screening program (median age: 53 years, 63\% females). Among participants not treated for diabetes, $3.7 \%$ had $\mathrm{RBG} \geq 7.8 \mathrm{mmol} / \mathrm{L}$ and $1.8 \%$ had both $\mathrm{RBG} \geq 7.0 \mathrm{mmol} / \mathrm{L}$ and $\mathrm{A} 1 \mathrm{c}$ $\geq 6.5$. Untreated blood pressure $\geq 140 / 90 \mathrm{mmHg}$ and/or untreated cholesterol $\geq 5.2 \mathrm{mmol} / \mathrm{L}$ were found in $50.5 \%$ of participants. One or several treated or untreated modifiable risk factors were found in $78 \%$ of participants. The telephone survey showed that $53 \%$ of all adults in the canton were sensitized by the campaign. Excluding fees paid by the participants, the program incurred a cost of CHF 330,600.

Conclusion: A community-based screening program had low efficiency for detecting new cases of diabetes, but it identified large numbers of persons with elevated other cardiovascular risk factors. Our findings suggest the convenience of A1c for mass screening of diabetes, the usefulness of extending diabetes screening to other cardiovascular risk factors, and the importance of a robust background communication campaign.

Keywords: hypertension, cholesterol, community-based program, evaluation, Switzerland

\section{Background}

Screening of diabetes and several risk factors for cardiovascular disease is recommended in asymptomatic adults, including those with smoking habits, high blood pressure, high cholesterol, and obesity. ${ }^{1-5}$ Screening of these conditions meet several criteria for mass screening, ${ }^{6,7}$ including high prevalence, silent evolution for several years, availability of simple diagnostic tests, and effective treatment for detected cases (behavioral or pharmacological). Screening programs for these conditions also have 
limitations, ${ }^{7-10}$ such as substantial cost, limited participation, false-positive cases, possibly false reassurance for negative cases, potential for social inequity, and uncertain evidence for health benefit associated with early detection in some instances.

There is no general consensus on target populations and screening tests for diabetes and cardiovascular risk factors. ${ }^{4}$ In addition, the usefulness of diabetes screening in the general population has been debated. ${ }^{2,11-15}$ Despite low efficiency of untargeted diabetes screening, ${ }^{14,16}$ there is a case for community-based screening of diabetes and main modifiable cardiovascular risk factors, besides advocacy and contingency arguments, since most adults harbor at least one risk factor for diabetes or cardiovascular disease. ${ }^{17-19}$

A community-based screening and awareness campaign was organized by the health department of the canton of Vaud as part of a new comprehensive diabetes program set up in response to the growing burden of diabetes. The campaign aimed at: (1) identifying new cases of diabetes and other uncontrolled cardiovascular risk factors, (2) raising awareness of diabetes and healthy lifestyles in the entire population, and (3) raising the overall visibility of the new diabetes program. The campaign comprised a screening component and an awareness component, which were expected to be mutually supportive. The fact that both diabetes and other cardiovascular risk factors share common risk behaviors was central to health advice given to all participants to the screening. ${ }^{20,21}$ Correspondingly, the need for a healthy diet and regular physical activity was the core message of the mass media campaign targeting the entire population.

While the impact of targeted screening programs is well documented, ${ }^{22,23}$ less information is available on mass screening programs through community outreach. ${ }^{16,24}$ The aim of this paper is to provide an account of a community-based screening program and an accompanying awareness campaign in the canton of Vaud in terms of impact, processes, main findings, and costs. These data may be useful to guide similar campaigns.

\section{Methods}

\section{Overall organization of the campaign}

A screening and awareness campaign for diabetes and other cardiovascular risk factors ("the campaign") was organized by the health department of the Vaud Canton, Switzerland, as part of a new diabetes program ("Programme cantonal Diabète") aimed at improving both primary and secondary prevention of diabetes. A working group of key stakeholders from several health sectors elaborated the campaign concept, which included two main components: (1) a screening component to take place in pharmacies of the canton targeting all adults, and (2) a mass media campaign targeting the general adult population of the canton (population aged 18 years or above, $\mathrm{N}=554,700$ ).

The actual implementation of the campaign was coordinated by one officer from the canton diabetes program during the 4 months from May to August 2010 and by two officers during the 4 months from September to December 2010 in close collaboration with the regional association of pharmacists (SVPh) and several other partners. The campaign, which took place on November 8-20, 2010, was launched during a press conference attended by the minister of health of the Canton, the main stakeholders of the campaign, and the mass media of the canton.

\section{The screening component of the campaign}

From a total of 244 pharmacies in the canton, 190 (78\%) participated in the screening component of the campaign, including 108 independent pharmacies and 82 pharmacies from the three groups of pharmacies. All pharmacies agreed to conduct the screening program along a common protocol specifically developed for the campaign. A six-page manual of procedures was prepared and distributed to all participating pharmacies. Pharmacists were trained through a 2-hour training session attended by around 300 of them, as well as through emails and hands-on training provided on site (particularly for the utilization of the "A1cNow" test). The distribution of the screening equipment to all pharmacies was organized centrally.

Questions to the participants enquired about: their age; place of residence; number of years elapsed since their last medical visit; history of diabetes in their first degree relatives; history of cardiovascular disease in their first degree relatives before the age of 60 years; current treatment for diabetes, dyslipidemia, or hypertension; number of hours since the last meal or beverage before the screening (except for water); smoking habits (number of cigarettes per day); practice of regular physical activity; and their interest in eating healthily.

Weight and height were measured, and optimal weight (corresponding to a body mass index of $25 \mathrm{~kg} / \mathrm{m}^{2}$ ) was calculated for each participant. Blood pressure was measured after a 5-minute rest in the sitting position. All pharmacies had an electronic sphygmomanometer prior to the campaign, although not the same models. A second reading was performed if blood pressure was $\geq 140 / 90 \mathrm{mmHg}$ in persons 
reporting no treatment for hypertension, and the average of the two blood pressure readings was considered.

A single finger stick was used for the measurement of both random blood glucose (RBG) and total cholesterol. RBG was determined in all participants with a glucometer (AccuCheck, Roche, Basel, Switzerland), which provides readings adjusted to plasma values. The coefficient of variation $(\mathrm{CV})$ of the test is $3 \%$ and $5 \%$ for low and high blood glucose values, respectively. When $\mathrm{RBG}$ was $\geq 7.0 \mathrm{mmol} / \mathrm{L}$ in persons unaware of having diabetes, a new finger stick was performed and A1c was measured (A1cNow, Bayer). The A1CNow test is simple to perform, and results are ready in 5 minutes. The $\mathrm{CV}$ of the test (including within-day and between-day) are $3.0 \%$ at low level and $4.0 \%$ at high level. The test is certified by the United States National Glycohemoglobin Standardization Program (NGSP). Total cholesterol was determined in all participants with a disposable 3-minute test (Chemcard Cholesterol, Chematics, North Webster, IN). Results were interpreted by matching the color of a strip with one of the six color blocks calibrated at $0.64 \mathrm{mmol} / \mathrm{L}$ increments between 3.9 and $7.8 \mathrm{mmol} / \mathrm{L}$. The test is registered by the United States Food and Drug Administration.

All results of the screening program, as mentioned above, were consigned by the attending pharmacists in an A5-sized card given to each participant within a plastic cover. The card was designed to allow the entry of readings for RBG and other risk factors on future visits. The card also displayed, using different colors, normal and borderline cutoff values for all tests performed during the screening program, and it also included health information on the main cardiovascular risk factors and healthy behaviors. Participants also received leaflets on diabetes and cardiovascular risk factors produced by partners of the campaign (Ligues de la santé, Swiss Cardiology Foundation, Association of Diabetes of Vaud Canton, program "Ça marche!").

Participants were free to decline any part of the screening. Participants were informed that their results would not be communicated to anyone and that it was the participant's decision to communicate results to their doctor. Participants were requested to sign a consent form if they agreed that their results be used for an aggregate analysis of the results of the campaign. Conditional to this agreement, the screening cards were photocopied and sent to the diabetes program center for data entry in an anonymous database. An amount of CHF 10 (approximately EUR 8) was charged by the pharmacists to each participant. Pharmacists also received CHF 10 from the health services for each test performed. The total cost for the disposable material utilized for one participant, accounting for one Alc test performed for every 10 participants, amounted to around CHF 9.

\section{The awareness component of the campaign}

The mass media campaign was mandated to a leading independent communication company (Bleu-Vert Communication, Lausanne, Switzerland), which worked in close collaboration with the organizers of the campaign, including the information section of the department of health of the canton of Vaud. The core message (in French) of the mass media campaign was "Don't nibble your health capital," which appeared in four different visuals showing healthy persons engaging in sedentary habits and/or eating unhealthy foods. All visuals included one of two main health messages ("A lack of physical activity may result in health problems" and "Unhealthy eating habits result in health problems") together with an invite for all adults to "screen for diabetes, cholesterol and blood pressure in a pharmacy of the canton" (Figure 1). The appearance of these health messages was designed to echo the layout of health warnings on cigarettes packets. A press release announcing the campaign was sent to all mass media and news agencies in the canton.

The visuals were displayed using different supports. Large billboards were placed in 250 outdoor public places in the canton during the 2-week campaign. Other large billboards were placed outside and inside of all the participating pharmacies. Flyers were made available in 360 public transport vehicles (buses and trains). Altogether, 12,000 screening cards, 2000 posters (A0, A1, A2), and 90,000 flyers were printed. Advertisements were placed in several newspapers. Advertisement spots were broadcast 165 times in the two main local radio stations. Several educational programs on diabetes were also organized on radio and TV and in several newspapers. Information was provided in the websites of the canton department of health (http://www.vd.ch/diabete) and other partners (eg, the diabetes association of the Vaud canton," Ligues de la santé," “Ça marche!” program, etc).

\section{Evaluation of the impact of the campaign targeting the general population}

A leading independent communication company in the region (MIS Trend, Lausanne, Switzerland) was mandated to perform an opinion poll about the campaign in the adult population of the canton of Vaud. Several officers of the company administered, a few days after the 2-week campaign, a computer-assisted telephonic interview to a representative sample of 504 inhabitants of the canton aged 18-74 years. 

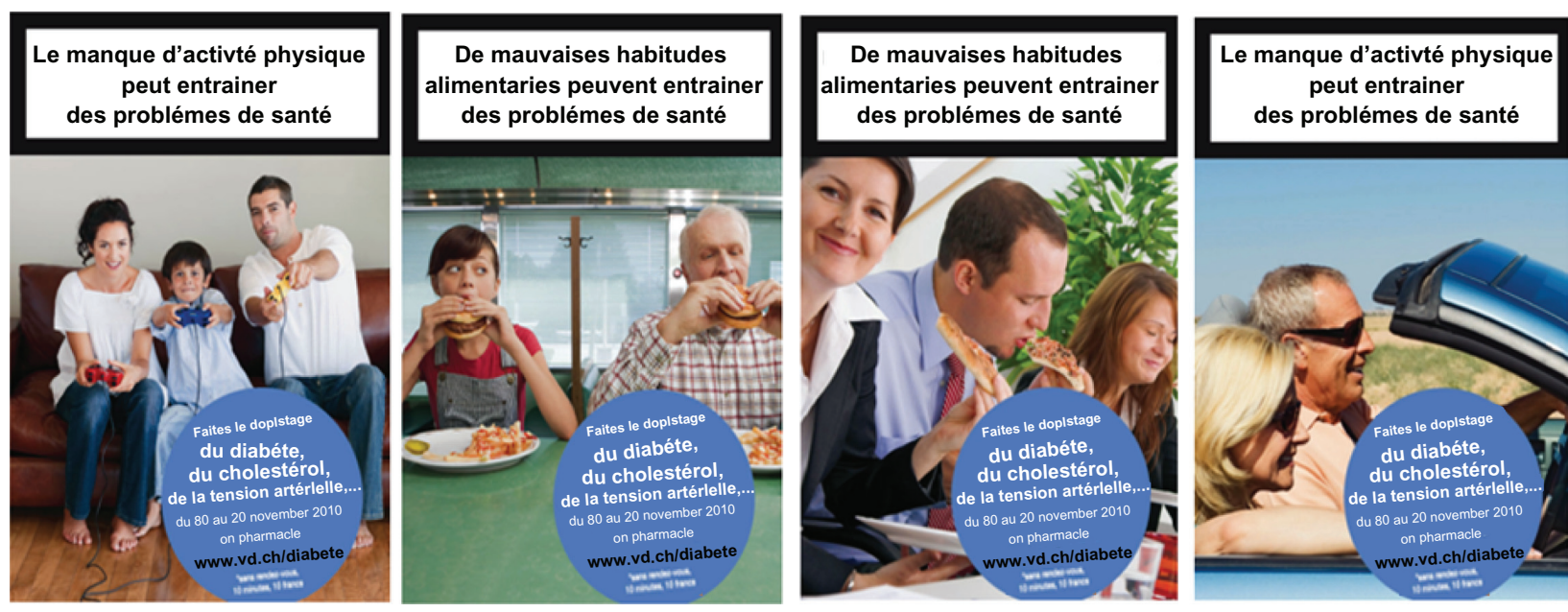

Figure I Visuals used in the mass media campaign targeting the general public. The visuals were created using pictures from Gettylmages ${ }^{\circledR}$ and iStockphotos ${ }^{\circledR}$.

\section{Evaluation of the screening by the pharmacists}

A few days after the campaign, the association of pharmacists of the canton of Vaud organized a Web-based survey among the pharmacists who participated in the screening. The survey enquired about different features of the screening program and how they perceived the participation of the screenees. The survey was completed by 106 (56\%) of the 190 pharmacists who had participated in the screening program.

\section{Results}

\section{Screening component}

The screening was attended by 4222 persons, ie, $0.76 \%$ of the population aged $\geq 18$ years of the canton. Few participants $(2.2 \%)$ declined to have their data used for aggregate analysis of screening results. Participation was higher during the second as compared with the first week $(69 \%$ and $31 \%$ of all participants, respectively), with no marked difference according to days of the week (approximately 400-500 persons per day during the second week). Around half of the participants were aged 55 years or above (median age, 53 years) and 67\% were female (Figure 2). Around half of the participants had visited a medical doctor during the past 12 months. This proportion was slightly higher in women than in men and it increased markedly with age (Figure 3).

The distribution of glucose impairment categories is shown in Table 1. Overall, 1.8\% of all participants reported being treated for diabetes.

Among persons not treated for diabetes, the prevalence of $\mathrm{RBG} \geq 5.6 \mathrm{mmol} / \mathrm{L}$ (a criterion for "impaired fasting glucose" if fasting blood glucose [FBG] is used ${ }^{25}$ ) was $44.1 \%$ overall, but the prevalence was only $34 \%$ among persons reporting having been fasting for $\geq 8$ hours. The prevalence of $\mathrm{RBG} \geq 7.0 \mathrm{mmol} / \mathrm{L}$ (a criterion for diabetes if $\mathrm{FBG}$ is used $^{25}$ ) was $8.8 \%$. This proportion was only $3.7 \%$ among persons reporting having been fasting for $\geq 8$ hours: this figure may represent a "best estimate" of the prevalence of undiagnosed diabetes in participants to the screening based on blood glucose results (as opposed to A1c results). The

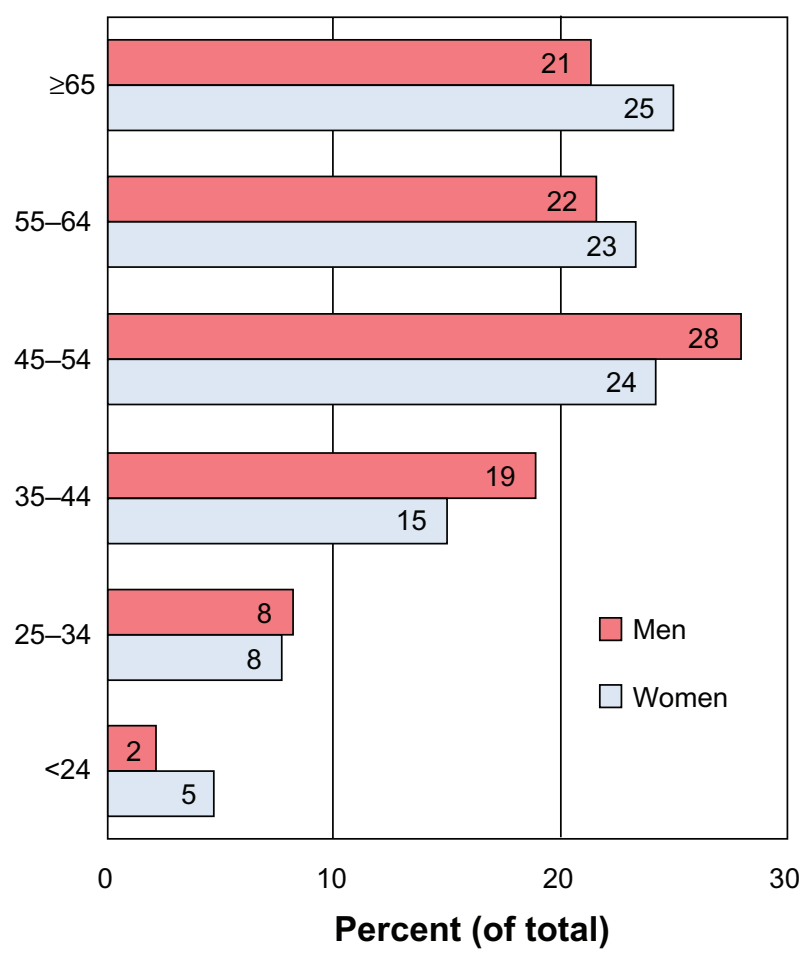

Figure 2 Distribution of the participants to the screening program according to age and sex. 


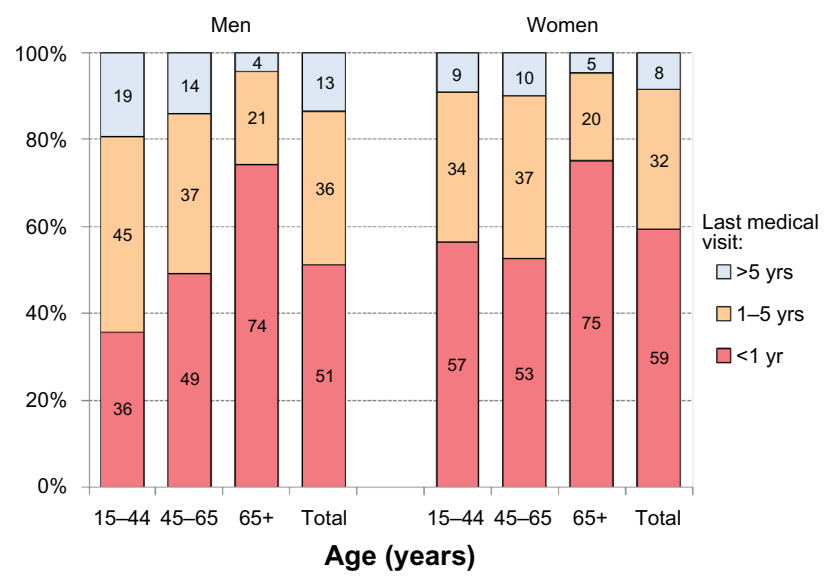

Figure 3 Distribution of the participants to the screening program according to sex, age, and last medical visit.

prevalence of $\mathrm{RBG} \geq 7.8 \mathrm{mmol} / \mathrm{L}$ (a criterion for "elevated glucose" if RBG is used ${ }^{25}$ ) was $3.7 \%$ overall but $5.9 \%$ in persons having been fasting for $<4$ hours. The prevalence of $\mathrm{RBG} \geq 11.0 \mathrm{mmol} / \mathrm{L}$ (a criterion for diabetes if $\mathrm{RBG}$ is used $^{25}$ ) was $0.4 \%$ overall but $0.6 \%$ in persons having been fasting for less than 4 hours.

A1c, which was expected to have been done in all persons not treated for diabetes who had $\mathrm{RBG} \geq 7.0 \mathrm{mmol} / \mathrm{L}$, had actually been performed in only $43 \%$ of them $(152 / 233)$. The prevalence of A1c $\geq 6.5$ (a criterion for diabetes in fasting and nonfasting persons ${ }^{25,26}$ ) was $20.4 \%$ in persons with $\mathrm{RBG} \geq 7.0 \mathrm{mmol} / \mathrm{L}$. Based on this proportion, 72 participants (ie, $1.8 \%$ of all untreated participants) would have had $\mathrm{A} 1 \mathrm{c} \geq 6.5$ if $\mathrm{A} 1 \mathrm{c}$ had been measured in all 355 participants who had $\mathrm{RBG} \geq 7.0 \mathrm{mmol} / \mathrm{L}$. This figure is likely our best estimate of the prevalence of suspected new cases of diabetes in the screening program.
The prevalence of pre-diabetes cannot be reliably determined in the screening program because we used RBG (and not FBG) and A1c was done only if RBG was $\geq 7.0 \mathrm{mmol} / \mathrm{L}$ (and not in participants with glucose between $5.6-7.0 \mathrm{mmol} / \mathrm{L}$ ). Some indication of the prevalence of prediabetes can however be derived from the prevalence of RBG ranging between 5.6 and $7.0 \mathrm{mmol} / \mathrm{L}$ (a criterion for prediabetes if FBG is used ${ }^{25,26}$ ) in the participants having been fasting for $\geq 8$ hours: this proportion was $30.4 \%$. Another indication of the prevalence of pre-diabetes could be derived from the prevalence of A1c ranging between 5.6 and 6.4 in the participants who were not fasting (eg, fast $<4$ hours).

The proportion of smokers was virtually identical in male and female participants (16.6\% versus $16.0 \%$, respectively), and $44 \%$ of all participants were overweight or obese. Between a quarter and a third of all participants had elevated blood pressure or elevated cholesterol and were not treated (Table 2), and 50.8\% had either or both of these untreated conditions. The proportion of untreated persons was substantially smaller in older than younger participants. A large majority of all participants had one or more treated or untreated cardiovascular risk factors.

Based on the survey conducted among the pharmacists after the screening campaign, the screening took $<10$ minutes for 3\% of participants, 10-15 minutes for 27\%, 15-20 minutes for 32\%, 20-25 minutes for 20\%, 25-30 minutes for $14 \%$, and $>30$ minutes for $4 \%$. Pharmacists reported that participants had heard about the screening program through promotional material from pharmacists ( $24 \%$ of participants), advertisements and programs on radio and TV (22\%), articles in newspapers (13\%), billboards in public places (9\%), and word of mouth $(5 \%)$. Pharmacists stated that nearly all

Table I Proportion of participants in the screening program with selected blood glucose impairment categories according to fasting duration

\begin{tabular}{|c|c|c|c|c|c|c|c|c|c|c|}
\hline & \multicolumn{6}{|c|}{ Number of hours since last meal/beverage } & \multicolumn{2}{|c|}{ Unknown } & \multicolumn{2}{|c|}{ Total } \\
\hline & \multicolumn{2}{|c|}{$<4$ hours } & \multicolumn{2}{|c|}{ 4-6 hours } & \multicolumn{2}{|c|}{$\geq 7$ hours } & \multirow[t]{2}{*}{$\mathbf{N}$} & \multirow[t]{2}{*}{$\%$} & \multirow[t]{2}{*}{$\mathbf{N}$} & \multirow[t]{2}{*}{$\%$} \\
\hline & $\mathbf{N}$ & $\%$ & $\mathbf{N}$ & $\%$ & $\mathbf{N}$ & $\%$ & & & & \\
\hline Data on treatment and RGB & 1828 & & 595 & & 804 & & 857 & & 4087 & \\
\hline Treated for diabetes & 32 & 1.8 & 11 & 1.9 & 12 & 1.9 & 12 & 1.5 & 70 & 1.8 \\
\hline Untreated for diabetes & 1796 & & 584 & & 792 & & 845 & & 4017 & \\
\hline $\mathrm{RBG} \geq 5.6$ & 960 & 53.5 & 184 & 31.5 & 270 & 34.1 & 358 & 42.4 & 1772 & 44.1 \\
\hline $\mathrm{RBG} \geq 7.0$ & 233 & 13.0 & 29 & 5.0 & 29 & 3.7 & 64 & 7.6 & 355 & 8.8 \\
\hline $\mathrm{RBG} \geq 7.8$ & 106 & 5.9 & 12 & 2.1 & 10 & 1.3 & 22 & 2.6 & 150 & 3.7 \\
\hline $\mathrm{RBG} \geq 1 \mathrm{I} .0$ & 10 & 0.6 & 2 & 0.3 & I & 0.1 & 3 & 0.4 & 16 & 0.4 \\
\hline \multicolumn{11}{|c|}{ Untreated for diabetes, RBG $\geq 7.0$ and $\mathrm{Alc}$ done } \\
\hline Number of participants & 95 & & 11 & & 19 & & 27 & & 152 & \\
\hline $\mathrm{RBG} \geq 7.0$ and $\mathrm{Alc}$ 5.7-6.4 & 31 & 32.6 & 5 & 45.5 & 10 & 52.6 & 16 & 59.3 & 62 & 40.8 \\
\hline $\mathrm{RBG} \geq 7.0$ and $\mathrm{Al} \mathrm{Ic} \geq 6.5$ & 17 & 17.9 & 2 & 18.2 & 7 & 36.8 & 5 & 18.5 & 31 & 20.4 \\
\hline
\end{tabular}

Abbreviation: RBG, random blood glucose ( $\mathrm{mmol} / \mathrm{L})$. 
Table 2 Proportion of participants in the screening program with selected cardiovascular risk factors, according to sex and age

\begin{tabular}{|c|c|c|c|c|c|c|c|c|c|c|}
\hline & \multicolumn{4}{|l|}{ Sex } & \multicolumn{4}{|l|}{ Age } & \multicolumn{2}{|l|}{ Total } \\
\hline & \multicolumn{2}{|l|}{ Men } & \multicolumn{2}{|c|}{ Women } & \multicolumn{2}{|l|}{$<55$} & \multicolumn{2}{|l|}{$\geq \mathbf{5 5}$} & \multirow[t]{2}{*}{$\mathbf{N}$} & \multirow[t]{2}{*}{$\%$} \\
\hline & $\mathbf{N}$ & $\%$ & $\mathbf{N}$ & $\%$ & $\mathbf{N}$ & $\%$ & $\mathbf{N}$ & $\%$ & & \\
\hline Total number of participants & 1367 & & 2735 & & 2157 & & I87| & & 4222 & \\
\hline \multicolumn{11}{|l|}{ Hypertension } \\
\hline Treated for hypertension & 188 & 14.3 & 333 & 12.7 & 90 & 4.4 & 423 & 23.3 & 521 & 13.2 \\
\hline Untreated and $\mathrm{BP} \geq 140 / 90$ & 466 & 35.4 & 569 & 21.7 & 436 & 21.2 & 589 & 32.5 & 1035 & 26.1 \\
\hline Untreated and $B P \geq 160 / 100$ & 121 & 9.2 & 145 & 5.5 & 99 & 4.8 & 164 & 9.0 & 263 & 6.6 \\
\hline$\%$ untreated among all with $\mathrm{HBP}^{\mathrm{a}}$ & & 71.3 & & 63.1 & & 82.9 & & 58.2 & & 66.5 \\
\hline \multicolumn{11}{|l|}{ EC } \\
\hline Treated for cholesterol (TC) & 119 & 9.1 & 177 & 6.8 & 57 & 2.8 & 235 & 13.1 & 292 & 7.4 \\
\hline Untreated and $\mathrm{TC} \geq 5.2$ & 453 & 34.7 & 939 & 36.1 & 619 & 30.3 & 748 & 41.7 & 1399 & 35.6 \\
\hline Untreated and TC $\geq 6.2$ & 138 & 10.6 & 325 & 12.5 & 180 & 8.8 & 271 & 15.1 & 451 & 11.5 \\
\hline$\%$ untreated among all with $\mathrm{EC}^{\mathrm{b}}$ & & 79.2 & & 84.1 & & 91.6 & & 76.1 & & 82.7 \\
\hline \multicolumn{11}{|l|}{ Overweight $\left(\mathrm{kg} / \mathrm{m}^{2}\right)$} \\
\hline Body mass index $\geq 25$ & 774 & 59.2 & 948 & 36.4 & 837 & 40.7 & 866 & 48.4 & 1703 & 44.3 \\
\hline Body mass index $\geq 30$ & 177 & 13.5 & 247 & 9.5 & 208 & 10.1 & 210 & 11.7 & 418 & 10.9 \\
\hline Cigarette smoking (yes/no) & 221 & 16.6 & 429 & 16.0 & 405 & 19.2 & 233 & 12.7 & 638 & 16.2 \\
\hline \multicolumn{11}{|c|}{ One or more of following risk factors (treated and untreated) } \\
\hline HBP, EC & 885 & 69.1 & 1505 & 58.8 & 951 & 47.4 & 1405 & 79.7 & 2397 & 62.2 \\
\hline HBP, EC, smoking & 936 & 74.2 & 1672 & 66.2 & 1139 & 57.5 & 1429 & 82.1 & 2616 & 68.8 \\
\hline HBP, EC, smoking, BMI $\geq 25$ & 1044 & 85.8 & 1814 & 74.6 & 1347 & 70.9 & 1468 & 87.2 & 2866 & 78.3 \\
\hline
\end{tabular}

Note: ${ }^{\mathrm{B} P \mathrm{P}} \geq 140 / 90 \mathrm{mmHg}$ or treatment for hypertension; ${ }^{\mathrm{C}} \mathrm{TC} \geq 5.2 \mathrm{mmol} / \mathrm{L}$ or cholesterol lowering treatment. Percentages with different conditions are calculated based on subsamples with no missing data.

Abbreviations: BMI, body mass index; BP, blood pressure; EC, elevated cholesterol; HBP, high blood pressure.

participants were very satisfied with both the screening and the quality of information provided.

\section{Awareness component}

The telephone survey conducted shortly after the screening campaign showed that the campaign was recalled by $7 \%$ of adults spontaneously and by $46 \%$ of adults passively (ie, with aid), hence by a total of $53 \%$ of all adults in the canton. Recall of the campaign was similar in large versus small towns and in men versus women, but it was larger in older than younger persons (Figure 4).

Among the $53 \%$ of adults who remembered the campaign, $61 \%-63 \%$ reported to have been sensitized "a lot" or "somehow" to the health promoting messages related to a healthy diet and regular physical activity (ie, the messages targeting the general population). With regards to the message advising members of the public to undergo a personal screening at a pharmacy to check for diabetes and risk factors, $45 \%-48 \%$ said they had been sensitized "a lot" or "somehow" (Figure 5). Hence, 33\% (ie, 53\% × 63\%, $\mathrm{N}=185,000$ persons) of all adults in the canton were sensitized to the health promoting messages, and $25 \%$ (ie, $53 \% \times 47 \%, \mathrm{~N}=138,000$ persons) to the importance of undergoing screening.
Among the $53 \%$ of all adults in the canton who remembered the campaign, $56 \%$ of them gathered information on the campaign from the billboards in public places, $38 \%$ from advertisements in newspapers, $33 \%$ from billboards around pharmacies, $26 \%$ from spots on radios, and $17 \%$ from the pharmacists' newsletters (which were sent at regular intervals to all households in the canton).

Table 3 shows selected findings related to perception by the general public about diabetes and about screening practices from the telephone survey in a representative sample of the population aged 18-74 of the canton of Vaud. Of note, the figure of $2 \%$ of all adults $(\mathrm{N}=3700)$ who said they participated to the screening is close to the 4222 persons who actually participated in the screening program.

\section{Budget of the campaign}

The main budget items are listed in Table 4. The total cost of the campaign amounted to approximately $\mathrm{CHF}$ 332,320 (approximately EUR 258,000). This amount does not take into account the CHF 10 fee paid by each participant to the pharmacists (CHF 42,000 in total). The communication campaign accounted for the largest part of the budget. 


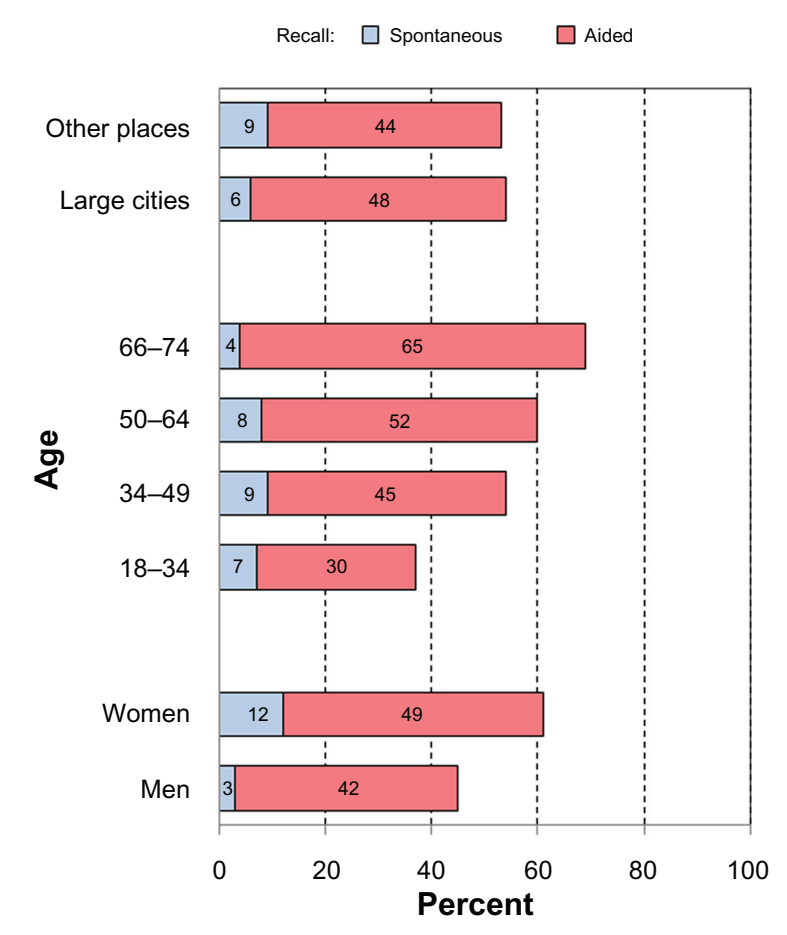

Figure 4 Recall of the mass media campaign by the general public (telephone survey of a representative sample of the population aged I8-74 in the canton of Vaud).

\section{Discussion}

We found that a 2-week community-based screening had a low impact for identifying new cases of diabetes, consistent with results in other community-based screening programs in the USA. ${ }^{13,14,16}$ Only $0.8 \%$ of all adults of the canton attended the screening, and between $1.8 \%$ and $3.7 \%$ (depending on which diagnostic criterion was used) of all persons not already treated for diabetes had a test result compatible with diabetes. However, the screening program was able to identify a large number of participants who had elevated other cardiovascular risk factors: $51 \%$ of all participants had high blood pressure or elevated cholesterol and no treatment. As many as $78 \%$ of participants had one or more treated or untreated risk factors and could benefit from health advice given by the pharmacists. The accompanying awareness campaign targeting the entire population succeeded in sensitizing approximately half of all adults in the canton.

We used a two-step strategy for diabetes screening: RBG in all participants followed by A1c if RBG was $\geq 7.0 \mathrm{mmol} / \mathrm{L}$ in persons unaware of having diabetes. The stepwise approach used in this screening program is practical (participants are not requested to be fasting) and it minimizes costs (A1c is performed for a minority of participants only); however, this is not standard practice, and the validity and cost-effectiveness of such a strategy should be evaluated. Furthermore, the small fee that individuals had to pay in order to participate in the screening program has likely limited participation rates although it is difficult to estimate the magnitude of this barrier. Since it is difficult to interpret the clinical significance of RBG (particularly for values in the intermediate range) and in view of the low attendance to a mass screening despite a strong communication campaign, a strategy based on A1c

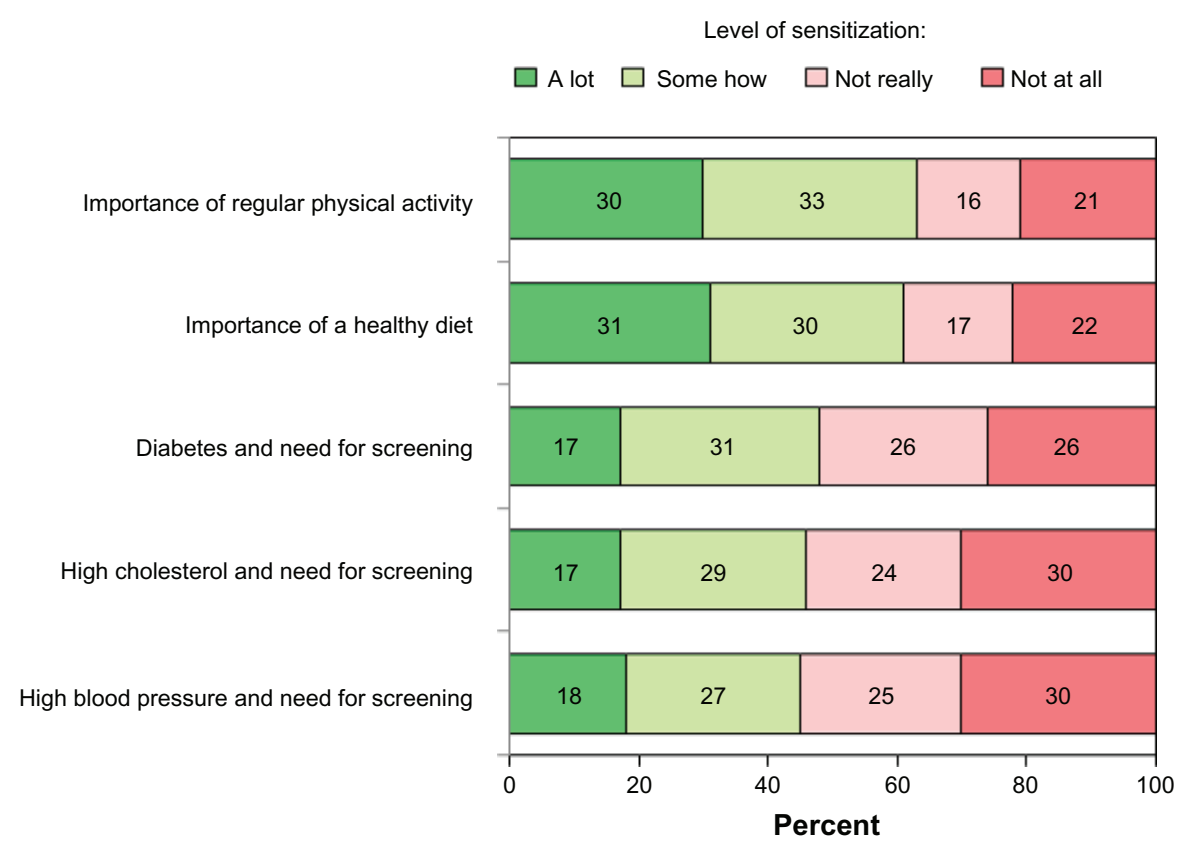

Figure $\mathbf{5}$ Levels of sensitization to different messages among members of the general public who could recall the campaign (telephone survey of a representative sample of the population aged $18-74$ in the canton of Vaud). 
Table 3 Perception of diabetes and screening practices in the general public (telephone survey of a representative sample of the population aged 18-74 of the canton of Vaud)

\begin{tabular}{|c|c|c|}
\hline Item & \multicolumn{2}{|l|}{ Percentage } \\
\hline \multicolumn{3}{|c|}{ Severity of diabetes as a disease } \\
\hline Very severe & \multicolumn{2}{|l|}{33} \\
\hline Quite severe & \multicolumn{2}{|l|}{61} \\
\hline Not severe & \multicolumn{2}{|l|}{6} \\
\hline \multicolumn{3}{|c|}{ Knows someone who has diabetes among relatives } \\
\hline All & \multicolumn{2}{|c|}{53} \\
\hline \multicolumn{3}{|c|}{ Underwent diabetes screening in past 12 months } \\
\hline All & \multicolumn{2}{|c|}{37} \\
\hline Men & \multicolumn{2}{|l|}{36} \\
\hline Women & \multicolumn{2}{|l|}{37} \\
\hline $18-34$ & \multicolumn{2}{|l|}{16} \\
\hline $35-49$ & \multicolumn{2}{|l|}{28} \\
\hline $50-64$ & \multicolumn{2}{|l|}{50} \\
\hline $65-74$ & \multicolumn{2}{|l|}{65} \\
\hline \multicolumn{3}{|c|}{ Among those screened, reason for doing screening } \\
\hline Own initiative & \multicolumn{2}{|c|}{49} \\
\hline Advice of a doctor & \multicolumn{2}{|l|}{47} \\
\hline Pressure from relatives & \multicolumn{2}{|l|}{2} \\
\hline Screening campaign & \multicolumn{2}{|l|}{2} \\
\hline \multicolumn{3}{|c|}{ Where would you find information on a health problem ${ }^{a}$} \\
\hline & Age 18-34 & Age $64-75$ \\
\hline Internet & 53 & 76 \\
\hline Doctor & 72 & 57 \\
\hline Pharmacist & 8 & 17 \\
\hline
\end{tabular}

Note: aSeveral answers possible.

only might be preferred for future community-based screening programs. ${ }^{27}$ An A1c-only strategy would be supported by the facts that (1) A1c is now an established criterion for assessing both diabetes and pre-diabetes, ${ }^{25,26}$ (2) A1c does not require fasting blood, and (3) the cost of the A1c test

Table 4 Broad cost categories for the screening and awareness campaign

\begin{tabular}{lr}
\hline Item & Cost (CHF) \\
\hline Printing screening cards, leaflets, and billboards & 44,800 \\
Posters in 250 public places & 33,700 \\
Placement of flyers in 350 public transport vehicles & 8,700 \\
Advertisements in three main & 20,700 \\
newspapers & \\
Production and airing of I65 spots on three local & 13,900 \\
radio stations & \\
Fees to communication company & 34,700 \\
Screening material and logistics & 21,000 \\
Data entry of screening results & 5,300 \\
Telephone survey in sample of general population & 10,800 \\
State support to pharmacists & 45,070 \\
Other expenses & 3,650 \\
Working time of project officers & 90,000 \\
Total & 332,320 \\
\hline
\end{tabular}

Note: The table does not include the CHF 10 subsidized fee paid by each participant for the screening (a total of CHF 42,000). (approximately EUR 7-8) is decreasing. Furthermore, a test that does not require FBG can also be particularly useful for identifying pre-diabetes, which may be more common than diabetes, ${ }^{28,29}$ and considering that effective interventions for the prevention of diabetes can be offered to pre-diabetic individuals. ${ }^{2,30}$ However, the validity of the A1c test for mass screening needs further appraisal in view of disagreement between diagnosis of diabetes based on blood glucose or A1c in some studies, ${ }^{31,32}$ although A1c was found to be a good diagnostic tool for diabetes in other studies. ${ }^{33,34}$ Disagreement between different diagnostic tests for diabetes is expected in view of the multifactorial pathophysiology of glucose dysfunction and the absence of a true criterion standard. Admittedly, differences between test results may have profound impact on the classification of the population identified as having pre-diabetes and diabetes.

The prevalence of diabetes based on our communitybased screening $(1.8 \%$ of cases treated $+1.8 \%$ of newly detected cases) was lower than the $6.6 \%$ diabetes prevalence at age 35-75 (with 66\% of them aware of the diagnosis) in a recent examination survey in the same region. ${ }^{29}$ This discrepancy might reflect both a "healthy participant effect," which may be stronger in this prevention campaign than in epidemiological surveys, and nonparticipation of some individuals already aware of having diabetes. The prevalence of several other cardiovascular risk factors strongly linked to socioeconomic status was also substantially lower in this screening program than in the population survey, ${ }^{29}$ respectively $16 \%$ versus $27 \%$ for the prevalence of smoking and $44 \%$ versus $52 \%$ for the prevalence of $\mathrm{BMI} \geq 25$. Of note, diabetes and pre-diabetes should be defined only on abnormal values confirmed on separate occasions. For example, a study in the USA showed that the true prevalence of diabetes was $24 \%$ lower than the prevalence estimated based on fasting blood sugar measured on only one visit. ${ }^{35}$

We found that half of all the participants to the screening had elevated blood pressure or elevated blood cholesterol and were not treated for these conditions. Although not all these persons should be treated because their total cardiovascular risk might not be elevated, ${ }^{3,36}$ a substantial proportion of them would benefit from medical management. Furthermore, nearly $80 \%$ of all participants to the screening had one or several modifiable risk factors (untreated or treated), and all of them would benefit from health advice. These findings strongly support the view that community-based screening programs of diabetes should include an assessment of all major modifiable cardiovascular risk factors, including health promoting advice to all participants that cuts across all risk 
factors. ${ }^{37}$ While identification and referral of persons with abnormal conditions is the main outcome of any screening program, health advice given by a health professional at the time of the screening can be highly cost-effective, eg, advice to quit smoking. ${ }^{1}$

Our screening program was accompanied by a strong communication campaign targeting the entire adult population with the double aim of informing the public about the screening and raising awareness on healthy lifestyles in the general population. Mass media campaigns that promote physical activity and healthy nutrition can have a positive impact, although they compete with pervasive product marketing, powerful social norms, and behaviors driven by addictions or habits. ${ }^{38}$ Therefore, media campaigns need to be organized at a large scale in order to be identified from the large flow of information from many concurrent sources. Although the "dose" of health education program delivered during a 2-week campaign is inherently limited, we cannot exclude a beneficial impact considering that half of all adults in the canton remembered the campaign and nearly a third of them $(88,000$ persons) reported to have been sensitized "a lot."

It is legitimate to enquire about the potential costeffectiveness of the community-based screening program and the related awareness campaign, knowing that "all screening programs do harm; some do good as well and, of these, some do more good than harm at reasonable cost"8 and that screening programs entail substantial opportunity costs. ${ }^{13}$ We don't know the actual uptake of health services for those participants who had a positive test (diabetes, hypertension, dyslipidemia) and no treatment in our screening program which can be very low in other contexts ${ }^{39}$ - and we know that the impact of individual-based advice for increasing physical activity or improving nutrition is generally only modest. ${ }^{40}$ However, we could argue that the program could be cost-effective if only a small percentage of the approximately 3000 participants who had one or several risk factors adopted a healthier behavior or initiated effective medical treatment and/or if a small proportion of the approximately 88,000 persons in the canton who were much sensitized by the mass media campaign had engaged in a healthier lifestyle. The campaign could cost less than CHF 300 per person adopting a healthy behavior or initiating effective treatment if more than 1000 persons (either screenees or members of the general public) had made such a change as a result of the campaign.

Furthermore, other variables should be factored when assessing the impact of community-based screening campaigns. For example, team building and involvement of new partners, which cannot be quantified in monetary units, are valuable outputs that may eventually turn into important resources for further programs tackling chronic diseases. In particular, it is increasingly recognized that community pharmacists have an important role for the delivery of health information to the general public, for the detection of new cases, and for improved management of chronic patients. ${ }^{41}$ New alliances may also turn into important resources when advocating for larger enrollment of the population into preventive strategies at health services level ${ }^{42}$ or for structural interventions cutting across all sectors for the prevention of diabetes and chronic conditions. ${ }^{43-46}$

The known problems of glucose-based screening with regards to valid identification of new diabetes cases, coupled with a low yield of new suspected cases, make community glucose-based screening unattractive. However, the large numbers of persons with abnormal levels of one or more cardiovascular risk factors, the increasing availability of simple screening tests, and the potential for capacity building processes suggest that a community-based screening program assessing diabetes together with the main cardiovascular risk factors might have acceptable efficiency despite low participation.

\section{Acknowledgments}

The authors wish to thank the many persons who collaborated to the campaign, particularly Pierre-Yves Maillard (chief of the Department of Health and Social Action, canton of Vaud), Jean-Christophe Masson (chief of the Public Health Service), Vlasta Mercier (chief of division, Department of Health), Vincent Girardin (Bleu-Vert Communication), Dr Brigitte Crottaz (endocrinologist), Franco Genovese (Ligues de la santé), Lise-Marie Gonzales and Aurore Gutschmidt (Diabetes Association of Canton of Vaud [AVD]), Alexia Fournier (program "Ça marche!”), Yves Kuhne (Health Management Network - RNB), Dr Angela Cottier (Association of Family Practitioners of Canton of Vaud - AMOV), Dr Jean-Pierre Pavillon (Medical Association of Canton of Vaud - SVM), Gaëlle Weston Bratschi (MIS Trend) and Felix Imhof (photographer). We also thank Michael Wilson, MPH, for useful input in the text.

We acknowledge the partial support from Roche (free supply of Accu-Check glucometers, strips and lancets), Bayer (reduced price for the A1cNow tests), and the wholesalers Amedis and Galexis (for assistance in assembling and delivering screening kits to pharmacies). 


\section{Disclosure}

All the authors participated in both the design and the conduct of the campaign but none of them received personal benefits from the sponsors. The views expressed by the authors of this paper do not necessarily reflect those of their institutions.

\section{References}

1. Maciosek MV, Coffield AB, Edwards NM, Flottemesch TJ, Solberg LI. Prioritizing clinical preventive services: a review and framework with implications for community preventive services. Annu Rev Public Health. 2009;30:341-355.

2. Li R, Zhang P, Barker LE, Chowdhury FM, Zhang X. Cost-effectiveness of interventions to prevent and control diabetes mellitus: a systematic review. Diabetes Care. 2010;33:1872-1894.

3. Greenland P, Alpert JS, Beller GA, et al. 2010 ACCF/AHA guideline for assessment of cardiovascular risk in asymptomatic adults: a report of the American College of Cardiology Foundation/American Heart Association Task Force on Practice Guidelines. Circulation. 2010;122:e584-e636.

4. Ferket BS, Colkesen EB, Visser JJ, et al. Systematic review of guidelines on cardiovascular risk assessment: Which recommendations should clinicians follow for a cardiovascular health check? Arch Intern Med. 2010;170:27-40.

5. US Preventive Services Task Force. Screening for obesity in adults: recommendations and rationale. Ann Intern Med. 2003;139:930-932.

6. Morrison SA. Screening in Chronic Disease. 2nd ed. Oxford University Press; 1992.

7. Strong K, Wald N, Miller A, Alwan A. Current concepts in screening for noncommunicable disease: World Health Organization Consultation Group Report on methodology of noncommunicable disease screening. J Med Screen. 2005;12:12-19.

8. Gray JA, Austoker J. Quality assurance in screening programmes. Br Med Bull. 1998;54:983-992.

9. Paddison CA, Eborall HC, Sutton S, et al. Are people with negative diabetes screening tests falsely reassured? Parallel group cohort study embedded in the ADDITION (Cambridge) randomised controlled trial. BMJ. 2009;339:b4535.

10. Narayan KM, Chan J, Mohan V. Early identification of type 2 diabetes: policy should be aligned with health systems strengthening. Diabetes Care. 2011;34:244-246.

11. Simmons RK, Echouffo-Tcheugui JB, Griffin SJ. Screening for type 2 diabetes: an update of the evidence. Diabetes Obes Metab. 2010; 12:838-844.

12. Waugh N, Scotland G, McNamee P, et al. Screening for type 2 diabetes: literature review and economic modelling. Health Technol Assess. 2007; 11:iii-xi, 1 .

13. Engelgau MM, Narayan KM, Herman WH. Screening for type 2 diabetes. Diabetes Care. 2000;23:1563-1580.

14. Newman WP, Nelson R, Scheer K. Community screening for diabetes. Low detection rate in a low-risk population. Diabetes Care. 1994; 17:363-365.

15. Norris SL, Kansagara D, Bougatsos C, Fu R. Screening adults for type 2 diabetes: a review of the evidence for the US Preventive Services Task Force. Ann Intern Med. 2008;148:855-868.

16. Tabaei BP, Burke R, Constance A, et al. Community-based screening for diabetes in Michigan. Diabetes Care. 2003;26:668-670.

17. Ford ES, Li C, Zhao G, Pearson WS, Capewell S. Trends in the prevalence of low risk factor burden for cardiovascular disease among United States adults. Circulation. 2009;120:1181-1188.

18. Kahn R, Alperin P, Eddy D, et al. Age at initiation and frequency of screening to detect type 2 diabetes: a cost-effectiveness analysis. Lancet. 2010;375:1365-1374.
19. Gillies CL, Lambert PC, Abrams KR, et al. Different strategies for screening and prevention of type 2 diabetes in adults: cost effectiveness analysis. BMJ. 2008;336:1180-1185.

20. Artinian NT, Fletcher GF, Mozaffarian D, et al. Interventions to promote physical activity and dietary lifestyle changes for cardiovascular risk factor reduction in adults: a scientific statement from the American Heart Association. Circulation. 2010;122:406-441.

21. Mozaffarian D, Kamineni A, Carnethon M, Djousse L, Mukamal KJ, Siscovick D. Lifestyle risk factors and new-onset diabetes mellitus in older adults: the cardiovascular health study. Arch Intern Med. 2009; 169:798-807.

22. Chamnan P, Simmons RK, Khaw KT, Wareham NJ, Griffin SJ. Estimating the population impact of screening strategies for identifying and treating people at high risk of cardiovascular disease: modelling study. BMJ. 2010;340:c1693.

23. Ealovega MW, Tabaei BP, Brandle M, Burke R, Herman WH. Opportunistic screening for diabetes in routine clinical practice. Diabetes Care. 2004;27:9-12.

24. Whitley EM, Main DS, McGloin J, Hanratty R. Reaching individuals at risk for cardiovascular disease through community outreach in Colorado. Prev Med. 2011;52:84-86.

25. American Diabetes Association. Diagnosis and classification of diabetes mellitus. Diabetes Care. 2010;33 Suppl 1:S62-S69.

26. International Expert Committee. International Expert Committee report on the role of the A1C assay in the diagnosis of diabetes. Diabetes Care. 2009;32:1327-1334.

27. Saudek CD, Herman WH, Sacks DB, Bergenstal RM, Edelman D, Davidson MB. A new look at screening and diagnosing diabetes mellitus. J Clin Endocrinol Metab. 2008;93:2447-2453.

28. Karve A, Hayward RA. Prevalence, diagnosis, and treatment of impaired fasting glucose and impaired glucose tolerance in nondiabetic US adults. Diabetes Care. 2010;33:2355-2359.

29. Firmann M, Mayor V, Vidal PM, et al. The CoLaus study: a populationbased study to investigate the epidemiology and genetic determinants of cardiovascular risk factors and metabolic syndrome. BMC Cardiovasc Disord. 2008;8:6.

30. Gillies CL, Abrams KR, Lambert PC, et al. Pharmacological and lifestyle interventions to prevent or delay type 2 diabetes in people with impaired glucose tolerance: systematic review and meta-analysis. $B M J$. 2007;334:299.

31. Olson DE, Rhee MK, Herrick K, Ziemer DC, Twombly JG, Phillips LS. Screening for diabetes and pre-diabetes with proposed A1C-based diagnostic criteria. Diabetes Care. 2010;33:2184-2189.

32. Mann DM, Carson AP, Shimbo D, Fonseca V, Fox CS, Muntner P. Impact of A1C screening criterion on the diagnosis of pre-diabetes among US adults. Diabetes Care. 2010;33:2190-2195.

33. Ackermann RT, Cheng YJ, Williamson DF, Gregg EW. Identifying adults at high risk for diabetes and cardiovascular disease using hemoglobin A1c national health and nutrition examination survey 2005-2006. Am J Prev Med. 2011;40:11-17.

34. Selvin E, Steffes MW, Gregg E, Brancati FL, Coresh J. Performance of A1C for the classification and prediction of diabetes. Diabetes Care. 2011;34:84-89.

35. Selvin E, Crainiceanu CM, Brancati FL, Coresh J. Short-term variability in measures of glycemia and implications for the classification of diabetes. Arch Intern Med. 2007;167:1545-1551.

36. Chamnan P, Simmons RK, Jackson R, Khaw KT, Wareham NJ, Griffin SJ. Non-diabetic hyperglycaemia and cardiovascular risk: moving beyond categorisation to individual interpretation of absolute risk. Diabetologia. 2011;54(2):291-299.

37. Lloyd-Jones DM, Hong Y, Labarthe D, et al. Defining and setting national goals for cardiovascular health promotion and disease reduction: the American Heart Association's strategic Impact Goal through 2020 and beyond. Circulation. 2010;121:586-613.

38. Wakefield MA, Loken B, Hornik RC. Use of mass media campaigns to change health behaviour. Lancet. 2010;376:1261-1271. 
39. Bovet P, Gervasoni JP, Mkamba M, Balampama M, Lengeler C, Paccaud F. Low utilization of health care services following screening for hypertension in Dar es Salaam (Tanzania): a prospective population-based study. BMC Public Health. 2008;8:407.

40. Lin JS, O'Connor E, Whitlock EP, Beil TL. Behavioral counseling to promote physical activity and a healthful diet to prevent cardiovascular disease in adults: a systematic review for the US Preventive Services Task Force. Ann Intern Med. 2010;153:736-750.

41. Carter BL, Rogers M, Daly J, Zheng S, James PA. The potency of team-based care interventions for hypertension: a meta-analysis. Arch Intern Med. 2009;169:1748-1755.
42. Kraushaar LE, Kramer A. Are we losing the battle against cardiometabolic disease? The case for a paradigm shift in primary prevention. BMC Public Health. 2009;9:64.

43. Gregg EW, Albright AL. The public health response to diabetes-two steps forward, one step back. JAMA. 2009;301:1596-1598.

44. [No authors listed]. Type 2 diabetes - time to change our approach. Lancet. 2010;375:2193.

45. Tuchman A. Diabetes and the public's health. Lancet. 2009;374: 1140-1141.

46. National Institute for Health and Clinical Excellence. Prevention of cardiovascular disease at population level. 2010.

\section{Publish your work in this journal}

Diabetes, Metabolic Syndrome and Obesity: Targets and Therapy is an international, peer-reviewed open-access journal committed to the rapid publication of the latest laboratory and clinical findings in the fields of diabetes, metabolic syndrome and obesity research. Original research, review, case reports, hypothesis formation, expert opinion and commentaries are all considered for publication. The manuscript management system is completely online and includes a very quick and fair peer-review system, which is all easy to use. Visit http://www.dovepress.com/testimonials.php to read real quotes from published authors.

Submit your manuscript here: http://www.dovepress.com/diabetes-metabolic-syndrome-and-obesity-targets-and-therapy-journal 